\title{
Title : Initiative of Sikkim District Mental Health Program
}

\author{
Dr Satish Rasaily \\ MD (Psychiatry), Addiction Medicine Specialist, District Nodal Officer (East Sikkim)
}

Suicide is one of the major public health problems in Sikkim and the State has been facing the dramatic rise in suicide cases. According to the National Crime Records Bureau (NCRB) report, 2008 Sikkim had the highest suicide rate and in 2009, Sikkim (39.9) was recorded as second highest state in the country in terms of suicide. The major cause of concern in Sikkim is the unusually high rate of suicide. Alcohol use is traditionally prevalent among Sikkim's population. National Family Health Survey-2, Government of India, has also highlighted a signi-ficant prevalence of alcohol use in Sikkim-32\% and 17\% among above 15 years of age males and females, respectively. From their observations prevalence of alcohol use is more common in rural areas than urban and negatively related to level of education and socioeconomic condition. These rough estimates make it obvious that alcohol use has become an important public health issue in Sikkim. As a result, abuse of opioids including heroin and other synthetic opioids have been reported from treatment centers. Similarly injection drug use (IDU) behavior has also been reported. Therefore, this is an early attempt to address the problem of substance abuse and mental Health problem in Sikkim.

\section{OBJECTIVES}

$>$ Develop strategy for prevention of mental illness.

> To promote Mental Health \& ensure availability and accessibility of mental health services to the vulnerable section of the society.

> Application of mental health knowledge to general health care of social development.

$>$ To promote community participation in mental health services development and to stimulate efforts towards self help in the community.

- To explore public health approaches to suicide prevention.

> Managements through early detection/ diagnosis/referral/follow up.

\section{Corresponding Author:}

Dr Satish Rasaily

(District Nodal Officer, DMHP, East Sikkim)

\section{ACTIVITIES UNDERTAKEN}

> The Psychiatric hospital with 24 bedded Indoor services at STNM Hospital, Gangtok has been functioning with an average of 30-40 patients per day with 24 hours emergency services integrated with emergency department of the hospital.

> Extensive Outreach Programme has been organized for identification of mentally disabled people.

> Orientation Training Programme for the awareness of the mental health is being imparted to the Medical Officer, Nursing Staff, Community Health Officers, PHNS, MPHW (Male / Female), Teachers Incharge of Police Personnel, Panchayat Members and Secretary and NGOs regularly.

> Health Education and IEC activities to bring awareness of Mental Health is being carried out to educate the general public through posters, booklets, pamphlets, audio visual publicity, dramas, radio talk etc. 
Title : Initiative of Sikkim District Mental Health Program

$>$ Outreach clinic at District Hospital at Singtam has been started covering 7 PHCs and 48 PHSCs under Singtam Hospital.

> The Mental Health Booklets both in English and Nepali version to educate the general public about mental illness depicted in pictorial form, showing the easy way to recognize the signs and symptoms of mental illness has been prepared.

- Emphasis has been given to the Media for promoting awareness among general people regarding mental illness by delivering programme in local newspapers focusing mental illness, suicide and drug addiction.

> Mental Health Programme has been started in all the four Districts and Sub-Divisions of the State.

$>$ Mental Health Awareness Programme regarding mental illness, Drug Addiction, Suicide and Adolescent Psychological problems has been started at different schools.
$>$ Suicide hotline services established for promotion of $24 \times 7$ counseling services to suicidal and mentally ill clients at times of crisis.

In convergence with $\mathrm{CATCH}$, attempt has been made to screen the population with depression, people with suicidal ideation and those who have attempted suicide and refer them to appropriate center for management. Attempt has been made to provide community based integrated Mental Health Care with support from appropriate Institute for management of mental illness and prevent suicide. Though till 2011-12 only East district was covered under District Mental Health Programme. However the programme has been extended to all 4 districts through mission flexi pool under NRHM. Therefore, Sikkim is perhaps the only state in India which has attempted to provide Mental Health services to rural population. 